\title{
Long-term management of gastroesophageal reflux disease with pantoprazole
}

\author{
Theo Scholten \\ Allgemeines Krankenhaus Hagen, \\ University of Witten/Herdecke, \\ Germany
}

Correspondence:Theo Scholten Allgemeines Krankenhaus Hagen, Gruenstr. 35, 58095 Hagen, Germany Tel +49 233I 2012246

Fax +49 2331 20I 2309

Email scholten@akh-hagen.de

\begin{abstract}
Gastroesophageal reflux disease (GERD) is a chronic, relapsing disease that can progress to major complications. Affected patients have poorer health-related quality of life than the general population. As GERD requires continued therapy to prevent relapse and complications, most patients with erosive esophagitis require long-term acid suppressive treatment. Thus GERD results in a significant cost burden and poor health-related quality of life. The effective treatment of GERD provides symptom resolution and high rates of remission in erosive esophagitis, lowers the incidence of GERD complications, improves health-related quality of life, and reduces the cost of this disease. Proton pump inhibitors are accepted as the most effective initial and maintenance treatment for GERD. Oral pantoprazole is a safe, well tolerated and effective initial and maintenance treatment for patients with nonerosive GERD or erosive esophagitis. Oral pantoprazole has greater efficacy than histamine $\mathrm{H}_{2}$-receptor antagonists and generally similar efficacy to other proton pump inhibitors for the initial and maintenance treatment of GERD. In addition, oral pantoprazole has been shown to improve the quality of life of patients with GERD and is associated with high levels of patient satisfaction with therapy. GERD appears to be more common and more severe in the elderly, and pantoprazole has shown to be an effective treatment for this at-risk population.
\end{abstract}

Keywords: pantoprazole, proton pump inhibitor, erosive esophagitis, gastroesophageal reflux disease, tolerability, efficacy

\section{Introduction}

Gastroesophageal reflux disease (GERD) is a chronic, relapsing disease that infrequently progresses (Sontag et al 2006) but is associated with a range of potentially serious esophageal complications (esophageal ulcer, esophageal stricture or obstruction, Barrett's esophagus or esophageal cancer) and extra-esophageal diseases such as respiratory problems, chest pain, angina, and increased mortality (Ruigomez et al 2004). It is characterized by reflux of the stomach contents into the esophagus, oropharynx, larynx, or airway and is associated with heartburn, acid regurgitation, and dyspepsia (Dent et al 1999; Farup et al 2001a; Shaker et al 2003; Orlando 2006). Other less common symptoms of GERD include cough, intermittent wheezing, vocal cord inflammation, atypical chest pain, dysphagia, and hoarseness. Simply put, GERD has been defined as "a condition which develops when the reflux of stomach contents causes troublesome symptoms and/or complications" (Vakil et al 2006).

Gastroesophageal reflux disease is one of the most common chronic gastrointestinal disorders (Haag and Holtmann 2003). It has been reported that GERD affects an estimated 19 million individuals in the US (Sandler et al 2002), and it can affect up to one-third of adults (Haag and Holtmann 2003). These figures are likely to underestimate the true prevalence of GERD, since many patients self-medicate and do not seek medical advice or diagnosis (Fendrick 2001). Similarly, many patients are 
not aware that they have GERD (Hollenz et al 2002). Failure to seek professional medical treatment can lead physicians to under-diagnose and under-treat GERD, with consequent poor control of symptoms, lost productivity, reduced quality of life, and an increased incidence of complications in affected patients. Ultimately, this under-diagnosis and under-treatment result in increased long-term healthcare utilization and costs.

This article provides an overview of GERD and the issues that must be considered during the long-term management of the disease; literature concerning the long-term treatment of GERD with the proton pump inhibitor (PPI) pantoprazole is then reviewed.

\section{Long-term management issues in GERD}

In healthy individuals, reflux of gastric contents occurs naturally without causing esophageal damage. However, in susceptible individuals, esophageal exposure to gastric contents causes either microscopic or macroscopic mucosal defects and the symptom of heartburn (Orlando 2006). The exact pathologic process by which this occurs is complex and yet to be fully characterized, but there are two requirements for heartburn, regardless of a diagnosis of erosive or nonerosive disease: these are high concentrations of acid within the esophageal lumen (reflux) and a damaged esophageal epithelium. When these situations co-exist, luminal acid enters the tissue where stimulation of nociceptors results in the symptom of heartburn (Orlando 2006). The major determinants of the severity of esophageal damage are the degree and duration of esophageal acid exposure in patients with impaired esophageal defenses (including increased frequency and duration of transient relaxations of the lower esophageal sphincter, impaired motility, decreased mucosal resistance, delayed gastric emptying, and presence of hiatus hernia) (Rai and Orlando 1998; Van Herwaarden et al 2000). In patients with nonerosive GERD, mucosal breaks are only apparent microscopically and are characterized by the presence of dilated intercellular spaces, whereas in patients with erosive esophagitis, breaks in the esophageal epithelium are visible on endoscopy. Nonerosive GERD can progress to erosive disease in susceptible patients (Orlando 2006) although initial severity of GERD is maintained in most patients (Vakil et al 2006). Erosive esophagitis is a chronic, recurring disease that can lead to further complications such as ulceration if long-term management is ineffective; secondary fibrosis and scarring can infrequently lead to esophageal stricture (Orlando 1999; Sontag et al 2006; Vakil et al 2006). A 20-year follow-up of 2306 patients who received symptom-driven antireflux treatment indicated that only one patient with a normal baseline mucosa developed esophageal stricture requiring dilation $(0.08 \%)$, but that 18 patients with an erosive baseline mucosa were affected $(1.9 \%)$. The overall incidence of stricture in patients with GERD was $<1 / 1,000$ per year (Sontag et al 2006).

With time, patients with GERD may develop histopathological changes such as Barrett's esophagus (Spechler and Goyal 1986). GERD and Barrett's esophagus are significant risk factors for esophageal adenocarcinoma (Lassen et al 2006; Vakil et al 2006), the incidence of which has increased in Western industrialized nations over the last two decades (Bollschweiler et al 2001). In 2002, the incidence of esophageal adenocarcinoma was 26 per 100000 person-years among patients with previously diagnosed erosive esophagitis (versus 2.79 per 100000 person-years in the general population) in a Danish community (Lassen et al 2006). The risk of this life-threatening cancer is greatest in patients with more severe, frequent, and prolonged symptoms of GERD (Lagergren et al 1999). Severe GERD (GERD characterized by erosions, ulcers, and strictures) occurs more frequently in men, the elderly, and those of white ethnicity than in other populations (El-Serag and Sonnenberg 1997). Infection with Helicobacter pylori does not appear to contribute to the development of GERD (Csendes et al 1997; Labenz and Malfertheiner 1997; Raghunath et al 2003; Sharma and Vakil 2003).

\section{Diagnosis}

The differential diagnosis of GERD is often difficult. The intensity and frequency of heartburn and other symptoms of GERD are poor predictors of the presence or severity of esophageal manifestations (Johansson et al 1986; Green 1993; Fennerty et al 2002) meaning that symptom assessment alone is not a reliable method to assess the presence or severity of erosive disease (Dent et al 1999; Johnson and Fennerty 2004). However, since objective testing is not common in primary practice, it has been suggested that GERD is likely when heartburn occurs on two or more days a week, although less frequent symptoms do not preclude disease (Dent et al 1999).

Initiation of empiric therapy with acid suppressive therapy, usually a PPI, in patients with symptoms consistent with GERD is an efficient and acceptable method to confirm GERD; this method lacks specificity (Numans et al 2004). 
If symptoms are relieved by therapy, a diagnosis of GERD can be assumed (DeVault and Castell 1999; Fass et al 1999, 2000; Habermann et al 2002). GERD can also be diagnosed using 24-hour $\mathrm{pH}$ monitoring, but this test has limitations because there is no direct information as to the extent of esophageal damage (Arango et al 2000). Additional confirmatory diagnostic tests include endoscopy, biopsy, barium radiography, examination of the throat and larynx, esophageal motility testing, emptying studies of the stomach, and esophageal acid perfusion. Of these tests, endoscopy is the only reliable method to diagnose erosive esophagitis and determine its severity (Tefera et al 1997).

\section{Aims of treatment}

The main aim of GERD treatment should be rapid and sustained achievement of comprehensive symptom resolution, because this is associated with marked improvement - often normalization - in health-related quality of life (Revicki et al 1999). The other primary aims are to heal esophageal mucosal damage if it is present and to prevent relapse of erosive esophagitis in the hope that this will reduce the development of other serious complications.

Adequate treatment of GERD should either prevent repeated reflux of gastric contents into the esophagus or reduce the damaging effect of gastric acid. As no pharmaceutical agent can fully correct the motor dysfunction responsible for acid reflux into the esophagus, acid suppression remains the most effective way to relieve symptoms and to promote healing of esophagitis in patients with GERD (Orlando 1997).

\section{Treatment options}

A number of pharmacological and surgical treatment options are available for patients with GERD. For most patients, initial acid suppressive therapy with a PPI is recommended. Once healing is achieved, the majority of patients with erosive esophagitis will require continued long-term (maintenance) acid suppressive treatment, usually with a lower dosage of their initial acidsuppressive therapy. This is because GERD is a chronic, usually lifelong disease that often relapses once treatment is stopped. In fact, relapse rates of $81 \%$ to $90 \%$ have been reported in patients with healed erosive esophagitis 6 to 12 months after drug therapy was withdrawn (Hetzel et al 1988; Chiba 1997; Carlsson et al 1998) and it is generally accepted that symptoms will persist in most patients (Vakil et al 2006).

\section{Pharmacological options}

The main acid suppressive agents available for patients with GERD are antacids, $\mathrm{H}_{2}$-receptor antagonists, and PPIs. Antacids do not usually provide sufficient acid suppression for patients with GERD. $\mathrm{H}_{2}$-receptor antagonists decrease gastric acid secretion by competitive and reversible blockade of histamine $\mathrm{H}_{2}$-receptors on the parietal cells of the gastric mucosa. $\mathrm{H}_{2}$-receptor antagonists are significantly more effective than antacids for suppressing acid secretion, but have a slower onset of action (Netzer et al 1998; Wyeth et al 1998). Use of $\mathrm{H}_{2}$-receptor antagonist is limited by drug tolerance, which can result in about a 50\% reduction in efficacy that cannot be reversed by dose increases (Nwokolo et al 1990; Kahrilas et al 1999). Over-the-counter preparations of low-dose $\mathrm{H}_{2}$-receptor antagonists (cimetidine, famotidine, nizatidine, and ranitidine) are also available. These are relatively safe, but are not effective in the vast majority of patients (Shaw et al 2001).

Proton pump inhibitors are widely recognized as the most effective agents for treating GERD. They are the mainstay of initial GERD management (DeVault and Castell 1999) and are the preferred agents for maintenance therapy in patients with healed erosive esophagitis (DeVault and Castell 1999; Crawley and Maclin Schmitt 2000). PPIs provide more rapid symptom control and better healing of erosive esophagitis than both $\mathrm{H}_{2}$-receptor antagonists and antacids (Chiba et al 1997; Dent et al 1999; DeVault and Castell 1999; Caro et al 2001; Donnellan et al 2004).

Proton pump inhibitors block the final step in the secretion of hydrochloric acid by binding to and inactivating $\mathrm{H}^{+} /$ $\mathrm{K}^{+}$ATPase in parietal cells of the gastric mucosa (Bell and Hunt 1992; Sachs 1997). PPIs thus produce a considerable but dose-dependent elevation of gastric $\mathrm{pH}$ (Dajani 2000). The prolonged hypochlorhydria seen with PPI therapy has raised safety concerns for patients receiving long-term therapy with these agents (possible enterochromaffin-like cell hyperplasia and gastric carcinoids, colorectal adenocarcinoma and polyps, and bacterial overgrowth as a result of achlorhydria). However, the magnitude of hypergastrinemia associated with PPI use is similar to that observed after vagotomy, and is 3-to 6-fold lower than that observed with pernicious anemia. Evidence to date indicates that any morphological changes in gastric endocrine cells are minimal, selflimiting, nondysplastic and non-neoplastic, suggesting that hypergastrinemia observed during PPI therapy has little clinical significance (Freston 1997). Thus, monitoring of serum gastrin levels and fundic enterochromaffin-like cells 
is of no clinical relevance even during long-term therapy with PPIs (Arnold 1994). PPIs are associated with a low rate of drug-drug reactions, other than those expected by the lowering of intragastric pH (Labenz et al 2003; Robinson and Horn 2003). Of the PPIs, omeprazole has the highest risk for hepatic-based interactions, and rabeprazole and pantoprazole appear to have the lowest risk (Robinson and Horn 2003). Of these lower risk agents, pantoprazole is the only PPI with a well characterized interaction profile (Blume et al 2006).

\section{Surgery}

Although surgery (open, endoscopic, or laparoscopic) is an option for some patients with GERD, the outcomes of corrective procedures vary widely depending on the experience and skill of the surgeon (Watson et al 1996; Johnson 2003). Surgery is not an ideal option for the majority of patients, and many patients will continue to use acid reducing medications on a regular basis after undergoing surgery (Spechler et al 2001; Johnson 2003). In comparison with pharmacotherapy in the US, surgical antireflux therapy (open Nissen fundoplication) produces no significant differences in grade of esophagitis, frequency of treatment of esophageal stricture, and subsequent antireflux operations, incidence of esophageal cancer, quality of life measures, and overall satisfaction with antireflux therapy when assessed more than 9 years after initiation of therapy (Spechler et al 2001). Similarly, in Europe, PPI therapy demonstrates similar efficacy to open antireflux surgery in terms of prevalence of Barrett's esophagus or strictures requiring dilatation, incidence of GERD-associated symptoms or quality of life at 3 years' follow up (Lundell et al 2000), but after 5 years is associated with lower total medical costs (operation, endoscopy, visits to the outpatient clinic, and medication) for chronic GERD (Myrvold et al 2001). Laparoscopic fundoplication is not without complications: surgical complications such as gastric perforation or hernia can occur; medical therapy is required for control of heartburn in approximately one third of patients after this procedure; and new gastric symptoms are common after surgery (Vakil et al 2003).

\section{Efficacy, safety, and tolerability of pantoprazole \\ Efficacy}

\section{Initial therapy}

Oral pantoprazole is an effective treatment option for the initial treatment of nonerosive GERD or erosive esophagitis. It is most effective for healing erosive esophagitis when administered at a dose of $40 \mathrm{mg}$ once daily (van Rensburg et al 1996; Richter and Bochenek 2000).

In patients with endoscopically confirmed mild to severe erosive esophagitis, oral pantoprazole $20 \mathrm{mg} /$ day or 40 $\mathrm{mg}$ /day is more effective for healing of erosions and relief of GERD symptoms than the $\mathrm{H}_{2}$-receptor antagonists with which it has been compared (Cheer et al 2003; Bochenek et al 2004) and generally has similar efficacy to other PPIs on a mg per mg basis (Cheer et al 2003; Scholten et al 2003; Gillessen et al 2004; Achim et al 2005; Glatzel et al 2006). Oral pantoprazole $20 \mathrm{mg}$ daily also provided clinical improvement in symptoms of erosive esophagitis in children aged 6 to 13 years enrolled in a small uncontrolled trial (Madrazo-de la Garza et al 2003). These latter findings are supported by the results of two recently completed studies. In these studies, oral pantoprazole at doses of $20 \mathrm{mg}$ and $40 \mathrm{mg}$ once daily for 8 weeks rapidly reduced symptom scores in 53 children aged 5 to 11 years with erosive or histological esophagitis $(\mathrm{p}<0.001)$ (Tolia et al 2006) and in 136 adolescents aged 12 to 16 years with clinically diagnosed GERD $(\mathrm{p}<0.001)$ (Tsou et al 2006). Pantoprazole $10 \mathrm{mg}$ daily also produced significant improvement in symptoms, but was not as effective as the higher doses in children (Tolia et al 2006).

\section{Maintenance therapy}

Pantoprazole $20 \mathrm{mg}$ or $40 \mathrm{mg}$ daily as maintenance therapy prevents relapse of erosive esophagitis for 6 to 24 months in most patients with healed disease (Mossner et al 1997; Escourrou et al 1999; Van Rensburg et al 1999; Plein et al 2000), regardless of patients' initial disease severity (Metz and Bochenek 2003; Richter et al 2004). Pantoprazole $20 \mathrm{mg}$ once daily has generally shown similar efficacy for preventing endoscopic or symptomatic relapse to pantoprazole $40 \mathrm{mg}$ once daily (Escourrou et al 1999; Plein et al 2000). In the larger of the two trials designed to statistically compare these pantoprazole regimens, daily doses of $20 \mathrm{mg}$ and 40 mg maintained $75 \%$ and $78 \%$ of patients, respectively, in endoscopic remission after 12 months, with Savary-Miller stage I disease accounting for about $50 \%$ of the endoscopic relapses (Plein et al 2000). Symptomatic remission rates after 12 months were also similar with each pantoprazole regimen: $77 \%$ with the $20 \mathrm{mg}$ dose and $76 \%$ with the $40 \mathrm{mg}$ dose. No correlation was seen between endoscopic relapse and perception of symptoms, or between the baseline severity of GERD and the maintenance dose of pantoprazole (Plein et al 2000). However, in two dose-ranging comparisons with ranitidine, patients receiving pantoprazole $40 \mathrm{mg}$ daily were 
significantly more likely to remain in remission than patients receiving pantoprazole $20 \mathrm{mg}$ daily $(\mathrm{p}<0.03$ and $\mathrm{p}<0.001)$ (Table 1) (Metz and Bochenek 2003; Richter et al 2004).

In comparisons with other active treatments, pantoprazole has demonstrated high remission rates. Pantoprazole 20 $\mathrm{mg}$ or $40 \mathrm{mg}$ is more effective than ranitidine $150 \mathrm{mg}$ once or twice daily for maintaining healing of GERD after 12 months of therapy (Table 1) (Adamek et al 2001; Metz and Bochenek 2003; Richter et al 2004). Patients receiving pantoprazole have significantly higher endoscopic remission rates at 12 months (Table 1) and symptomatic control is also significantly better, as measured by the proportion of symptom-free patients at 12 months (Table 1) (Adamek et al 2001), the number of symptom-free days during the 12-month period $(83 \%$ of days vs $58 \%$ of days, p $<0.001$ [Richter et al 2004] and 78\% vs 48\%, p < 0.001 [Metz and Bochenek 2003]) and the number of nights without heartburn $(93 \%$ of nights vs $77 \%$ of nights, $\mathrm{p}=0.001$ [Richter et al 2004] and, $\mathrm{p}=0.002$ [Metz and Bochenek 2003]). In addition, pantoprazole maintains patients in remission for a longer period of time than does ranitidine (Metz and Bochenek 2003). Pantoprazole is more effective than ranitidine in maintaining endoscopically confirmed healing, regardless of initial disease severity or H. pylori status (Metz and Bochenek 2003, Richter et al 2004).

Only a few studies have evaluated the efficacy of maintenance therapy with pantoprazole in comparison with other PPIs. The data available indicate that pantoprazole 20 $\mathrm{mg}$ has similar efficacy to omeprazole $20 \mathrm{mg}$ for maintaining endoscopic and symptomatic remission in patients with healed erosive esophagitis (Lauritsen et al 2000). In comparisons with esomeprazole $20 \mathrm{mg}$ daily, there are two studies showing conflicting results. Whereas the study by Labenz and colleagues (2005) showed esomeprazole $20 \mathrm{mg}$ daily to be superior to pantoprazole $20 \mathrm{mg}$ daily, the study by Goh and colleagues (2007) showed esomeprazole $20 \mathrm{mg}$

Table I Randomized clinical trials comparing the efficacy of maintenance therapy with pantoprazole versus other acid suppressing agents in patients with healed erosive esophagitis ${ }^{\mathrm{a}}$

\begin{tabular}{|c|c|c|c|}
\hline Reference & Treatment (No of patients) & $\begin{array}{l}\text { Endoscopic } \\
\text { remission } \\
\text { rate at study } \\
\text { end (\% patients) }\end{array}$ & $\begin{array}{l}\text { Symptomatic } \\
\text { control } \\
\text { at study end } \\
\text { (\% patients) }\end{array}$ \\
\hline \multicolumn{4}{|c|}{ Comparisons with other proton pump inhibitors } \\
\hline Goh et al 2007 & Pantoprazole $20 \mathrm{mg}$ once daily (636) & & \\
\hline (double-blind, 6-month trial) & Esomeprazole $20 \mathrm{mg}$ once daily (667) & & \\
\hline Labenz et al 2005 & Pantoprazole $20 \mathrm{mg}$ once daily (1389) & $77^{* *}$ & $88.5^{*}$ \\
\hline (double-blind, 6-month trial) & Esomeprazole $20 \mathrm{mg}$ once daily (1377) & 88 & 92 \\
\hline Lauritsen et al 2000 & Pantoprazole $20 \mathrm{mg}$ once daily $(2 \mathrm{II})$ & 77 & 83 \\
\hline \multirow[t]{2}{*}{ (double-blind, I 2-month trial) } & Pantoprazole $40 \mathrm{mg}$ once daily (218) & 83 & 87 \\
\hline & Omeprazole $20 \mathrm{mg}$ once daily $(2 \mathrm{I} 0)$ & 81 & 86 \\
\hline \multicolumn{4}{|l|}{ Comparisons with ranitidine } \\
\hline Adamek et al $200 \mathrm{I}$ & Pantoprazole 20 mg once daily(199) & $66^{* *}$ & $73 \%^{*}$ \\
\hline (double-blind, I2-month trial) & Ranitidine 150 mg once daily (104) & 34 & $65 \%$ \\
\hline Metz et al 2003 & Pantoprazole 10 mg once daily (89) & 40 & \\
\hline \multirow[t]{3}{*}{ (double-blind, I2-month trial) } & Pantoprazole $20 \mathrm{mg}$ once daily (93) & 68 & \\
\hline & Pantoprazole $40 \mathrm{mg}$ once daily (94) & 82 & \\
\hline & Ranitidine $150 \mathrm{mg}$ twice daily (95) & $33^{\dagger}$ & \\
\hline Richter et al 2004 & Pantoprazole $10 \mathrm{mg}$ once daily (88) & 46 & \\
\hline \multirow[t]{3}{*}{ (double-blind, I2-month trial) } & Pantoprazole $20 \mathrm{mg}$ once daily (88) & $55^{*}$ & \\
\hline & Pantoprazole $40 \mathrm{mg}$ once daily (85) & $78^{*}$ & \\
\hline & Ranitidine $150 \mathrm{mg}$ twice daily (88) & 21 & \\
\hline
\end{tabular}

Note: ${ }^{2}$ Results of intention-to-treat analyses; ${ }^{b}$ Endoscopic plus symptomatic control; ${ }^{*} \mathrm{p}<0.00 \mathrm{I} ;{ }^{* *} \mathrm{p} \leq 0.000 \mathrm{I}$ versus esomeprazole or ranitidine; ${ }^{\dagger} \mathrm{p}<0.00 \mathrm{I}$ versus all doses of pantoprazole. 
daily to be as effective as pantoprazole $20 \mathrm{mg}$ daily in keeping patients in combined endoscopic and symptomatic remission (Table 1).

In the above trials the symptoms assessed were heartburn, dysphagia or pain on swallowing, and acid regurgitation. In some instances, additional gastric symptoms were also included (Plein et al 2000; Labenz et al 2005), but longterm data regarding the efficacy of pantoprazole for control of respiratory or laryngeal symptoms of GERD are not available. However, long-term high-dose PPI therapy is the first-line approach to controlling these extraesophageal GERD symptoms (Halstead 2005).

Pantoprazole has also demonstrated efficacy in difficultto-treat patients. In 66 patients with aggressive, complicated GERD refractory to $\mathrm{H}_{2}$-receptor antagonists, but healed with oral pantoprazole, continued therapy with oral pantoprazole $40 \mathrm{mg}$ daily maintained remission in most patients at 24 months (percentages were not reported) (Bardhan et al 2001).

It is common for many patients with mild disease and infrequent symptom relapses to use a PPI only when symptoms demand. Patients with symptomatic or mild erosive GERD are therefore ideal candidates for on-demand or intermittent treatment (Bardhan 2003). On-demand treatment with oral pantoprazole $20 \mathrm{mg}$ or $40 \mathrm{mg}$ daily provided effective symptomatic control in 634 patients with endoscopically confirmed Savary-Miller grade 0/I GERD and heartburn, with the mean perceived average daily symptom load of heartburn over a 6-month period reduced from 3.93 with placebo to 2.71 with the $40 \mathrm{mg}$ dose and 2.91 with the 20 $\mathrm{mg}$ dose $(\mathrm{p}<0.0001$ for both pantoprazole doses vs placebo) (Scholten, Dekkers, et al 2005). The discontinuation rate due to insufficient control of heartburn or unsatisfactory treatment (insufficient control of heartburn or other gastrointestinal symptoms) was significantly lower in both pantoprazole groups than in the placebo group, despite placebo recipients using significantly more antacid therapy $(\mathrm{p}<0.05$ for all pantoprazole vs placebo comparisons). No significant differences between pantoprazole $20 \mathrm{mg}$ and $40 \mathrm{mg}$ were reported.

These advantages of on-demand pantoprazole over placebo for control of heartburn were confirmed for a wider range of GERD-associated symptoms in another trial. Ondemand treatment with pantoprazole $20 \mathrm{mg}$ for 6 months was effective, compared with placebo, in maintaining control of the symptoms of heartburn, acid regurgitation, and pain on swallowing in 439 patients with healed Savary-Miller grade 0/I GERD. Patients' perceived average daily symptom load was 1.5 and 2.2 for the pantoprazole and placebo group, respectively $(\mathrm{p}<0.05)$, and pantoprazole-treated patients experienced fewer episodes requiring treatment $(\mathrm{p}<0.01)$, and had a lower discontinuation rate due to insufficient control of symptoms or unsatisfactory treatment. Again, antacid usage was significantly higher in placebo recipients than in pantoprazole-treated patients $(\mathrm{p}<0.05)$ (Kaspari et al 2005).

In the only identified comparison of on-demand administration of active treatments, pantoprazole $20 \mathrm{mg}$ significantly reduced the symptom load for heartburn compared with esomeprazole $20 \mathrm{mg}$ (1.12 vs $1.32, \mathrm{p}=$ 0.0115 ) in 199 patients with Los Angeles classification grade A or B GERD or nonerosive GERD and moderate or severe heartburn. Mean intensities of heartburn were significantly lower in the pantoprazole compared with the esomeprazole treatment group during the 6 months on-demand treatment (1.10 vs 1.33, $\mathrm{p}=0.0096$ ) (Figure 1) (Scholten, Bohuschke, et al 2005).

\section{Safety and tolerability}

Results of numerous clinical trials indicate that oral pantoprazole is safe and well tolerated for short-term treatment of GERD and for longer term maintenance therapy in patients with healed erosive esophagitis. Oral pantoprazole at dosages of up to $40 \mathrm{mg}$ daily was safe and well tolerated in studies of 1 to 2 years in duration (Mossner et al 1997; Escourrou et al 1999; Van Rensburg et al 1999; Plein et al 2000; Adamek et al 2001; Metz and Bochenek 2003; Richter et al 2004; Labenz et al 2005). Although serum gastrin levels tended to increase initially in some, but not all, studies, they generally stabilized and were not associated with adverse histological findings. Adverse events most commonly experienced by patients receiving pantoprazole in these long-term trials are those expected in patients receiving PPI therapy. Events most frequently include diarrhea, nausea, vomiting, headache, dizziness, abdominal pain, infection, and raised liver enzymes. These are usually of mild to moderate intensity and seldom necessitate discontinuation of treatment.

Two longer-term trials have been performed. One reported data for treatment with oral pantoprazole for up to 3 years. In this study, only 4 of 111 patients had adverse events definitely related to pantoprazole. Elevations in gastrin were modest and there were no significant changes in gastric endocrine cells (Bardhan et al 2001). The other 


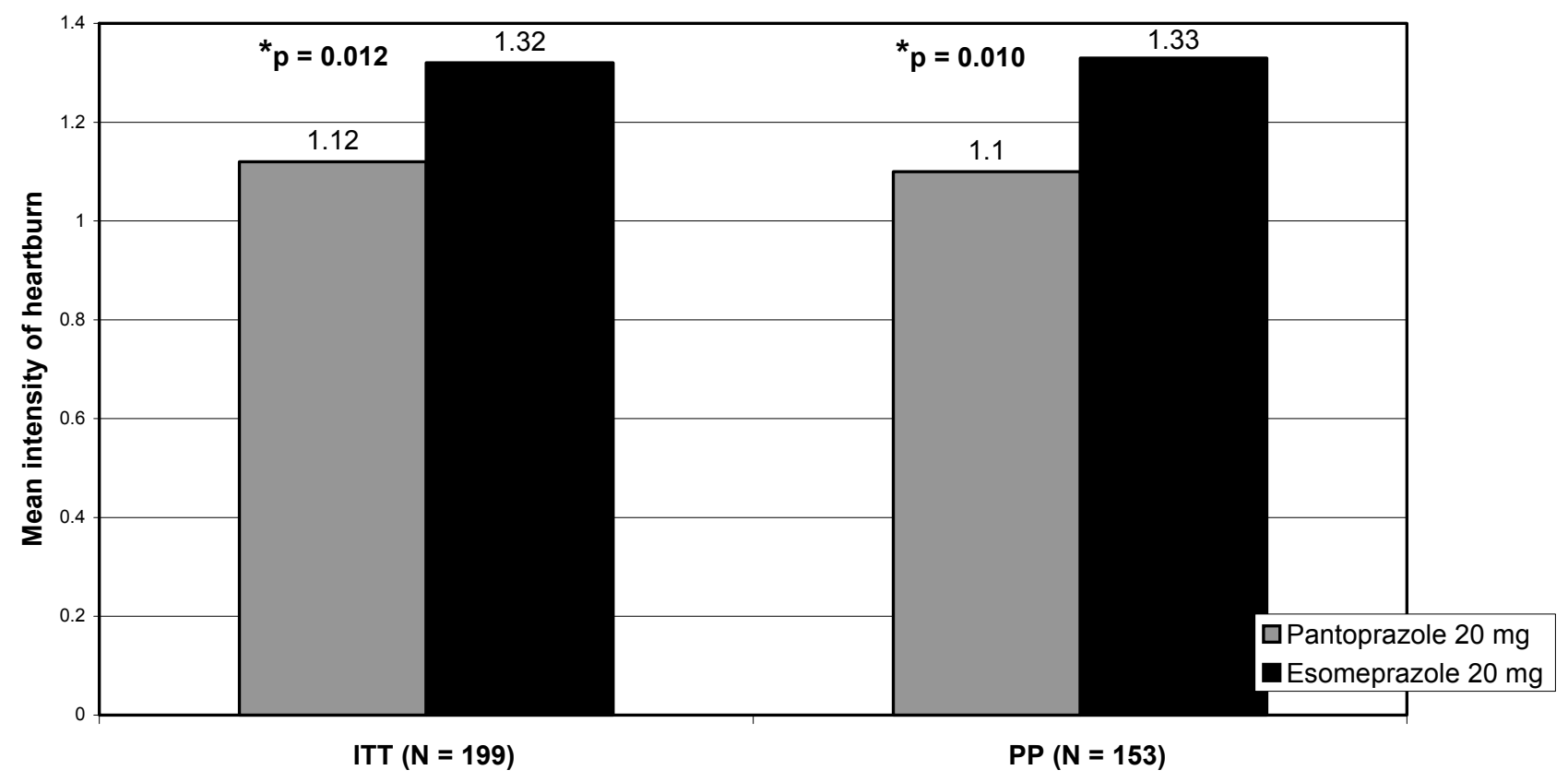

Figure I On-demand therapy with pantoprazole leads to lower heartburn intensity than with esomeprazole in patients with mild GERD. Note: "Statistically significant difference; The intensity of symptoms was rated on a 4 point-scale (0: none, I: mild, 2: moderate, 3: severe). Abbreviations: ITT, intention to treat population; PP, per protocol population.

is an ongoing 10-year study, in which maintenance therapy with pantoprazole $40 \mathrm{mg}$ to $160 \mathrm{mg}$ daily was well tolerated in patients with healed peptic ulcers or erosive esophagitis. There were no increases in signs associated with an enhanced risk of gastric cancer, although fasting serum gastrin levels increased slightly after the second year of treatment but remained at this level thereafter. Of 134 patients originally enrolled in this long-term study, 99 patients were treated with pantoprazole for at least 5 years, and 25 had completed 10 years of treatment (Heinze et al 2003).

The safety profile of pantoprazole in elderly patients is discussed later in this review. Short-term (up to 8 weeks) use of pantoprazole is safe and well tolerated in children and adolescents (aged 5 to 16 years) (Madrazo-de la Garza et al 2003; Tolia et al 2006; Tsou et al 2006).

\section{Impact of GERD on quality of life}

Patients with GERD have significantly $(\mathrm{p}<0.05)$ poorer health-related quality of life than the general population (McDougall et al 1996; Revicki et al 1998; Enck et al 1999; Kaplan-Machlis et al 1999; Farup et al 2001a; Pare et al 2003), patients with diabetes or hypertension (Revicki et al 1998; Enck et al 1999), and patients with severe angina pectoris or mild heart failure (Dimenas et al 1993). Although there are no relevant differences in health-related quality of life between patients with Barrett's esophagus, erosive esophagitis and non-erosive GERD (Kulig et al 2003), impairment is proportional to the frequency and severity of symptoms, regardless of the presence or absence of esophagitis (Dimenas et al 1996; Dent et al 1999; KaplanMachlis et al 1999), is more severe in females and younger patients (Holtmann et al 2006b) and is exacerbated by the presence of nocturnal symptoms (Farup et al 2001a, 2001b). Although the frequency and intensity of acid complaints significantly influence the health-related quality of life of patients with GERD (Holtmann et al 2006a), a number of other gastrointestinal symptoms, such as upper abdominal/ stomach complaints, lower abdominal/digestive complaints, and nausea, also have a major role (Malagelada et al 2006). The impact of GERD is most striking on measures of pain, mental health, and social function (Revicki et al 1998; Enck et al 1999; Farup et al 2001a). The presence of GERD is also associated with reduced work productivity for affected individuals in the labor force (Henke et al 2000; Sandler et al 2002).

The treatment of GERD improves symptoms and healthrelated quality of life outcomes (Wiklund et al 1998; Revicki et al 1999; Prasad et al 2003). Control of heartburn strongly 
predicts improvement in health-related quality of life during the acute treatment of GERD (Pare et al 2003). Although no trials of maintenance therapy have reported quality of life assessments for pantoprazole, several studies have evaluated the effect of short-term pantoprazole on health-related quality of life, and results of these studies generally showed the PPI to improve health-related quality of life (de-Souza-Cury et al 2006) and be superior to $\mathrm{H}_{2}$-receptor antagonists (Kaspari et al 2001; Pare et al 2003). Health-related quality of life improved more rapidly and to a greater extent following treatment with pantoprazole $40 \mathrm{mg}$ once daily compared with nizatidine $150 \mathrm{mg}$ twice daily in a total of 208 patients with GERD characterized by heartburn (with or without erosive esophagitis). After 7 days, scores for all assessment scales improved more with pantoprazole than nizatidine. Patients receiving pantoprazole showed significantly greater improvement in two SF-36 domains, bodily pain $(\mathrm{p}<0.01)$ and vitality $(\mathrm{p}<0.05)$, and in the gastrointestinal system rating scale (GSRS) reflux score $(\mathrm{p}<0.01)$. After 28 days of treatment, the changes in scores relative to baseline were still greater with pantoprazole than with nizatidine (Pare et al 2003). Similarly, in comparison with ranitidine, quality of life parameters tended to improve more with pantoprazole $20 \mathrm{mg}$ once daily than ranitidine $150 \mathrm{mg}$ twice daily according to the gastrointestinal quality of life index (GIQLI) and SF-36, with a significant advantage seen for pantoprazole in the SF36 vitality score $(\mathrm{p}<0.05)$, in a mixed population of patients with nonerosive GERD or endoscopically confirmed erosive esophagitis. Patients' assessment of treatment also appeared to be more favorable for pantoprazole in this short-term study (Kaspari et al 2001). Patient satisfaction with treatment is similar with pantoprazole, omeprazole, and lansoprazole (at 4 and 8 weeks, respectively, patient satisfaction was $79 \%$ and 91\% [pantoprazole], 79\% and 89\% [omeprazole multiple unit pellet system (MUPS)] and 76\% and 86\% [lansoprazole] in one study [Mulder et al 2002]).

Recently, a new GERD specific, reliable, sensitive, and validated questionnaire for the evaluation of health-related quality of life was developed. The GERDyzer ${ }^{\mathrm{TM}}$ covers 10 dimensions of quality of life (general well-being, pain/ discomfort, physical health, energy, daily activities, leisure activities, social life, diet/eating/drinking habits, mood and sleep) and has demonstrated very high internal consistency, good test-retest reliability, responsiveness and construct validity in patients treated with pantoprazole (Holtmann et al 2005). Using this questionnaire in conjunction with the ReQuest ${ }^{\mathrm{TM}}$ - GI (Stanghellini V et al 2005), all dimensions of treatment satisfaction were shown to increase during 4 weeks of treatment with pantoprazole, with good treatment satisfaction reported after the first week of therapy (DeVault et al. 2006).

Treating patients with GERD is about 2-fold more costly than treating those without GERD (Bloom et al 2001). However, PPIs have the lowest total cost per patient of the available pharmacological treatments, when total costs (defined as the costs of diagnosis and initial treatment, and the costs associated with treatment success, treatment failure and remission) are calculated, despite having higher acquisition costs than other acid suppressive agents (Holzer et al 1998). Scant pharmacoeconomic data specific for pantoprazole are available. The only study identified, a modelling study in the Netherlands, showed that pantoprazole may have a more favorable pharmacoeconomic profile than omeprazole. Assumptions were based on available documentation concerning the effectiveness and costs of omeprazole and pantoprazole and findings are only valid if the substitution of omeprazole by pantoprazole can be achieved without loss of efficacy or tolerability (van Hout et al 2003).

\section{Special considerations in the elderly}

GERD appears to be more common and more severe in the elderly than in younger individuals; in fact age is an important risk factor for the development of severe forms of GERD (El-Serag and Sonnenberg 1997; Johnson and Fennerty 2004). In the primary care setting in the US, as many as $20 \%$ of older patients report acid reflux (Mold et al 1991), and in a Japanese study, the prevalence of erosive esophagitis in patients aged $>70$ years was more than triple the prevalence in patients younger than 39 years (Maekawa et al 1998). In common with the general population, the intensity and frequency of heartburn and other symptoms of GERD are poor predictors of the presence or severity of esophageal manifestations. In addition, older patients are less likely to experience severe heartburn than younger patients (Johnson and Fennerty 2004) and the majority (over 75\%) do not experience acid regurgitation as an initial symptom (Räihä et al 1991; Pilotto and Franceschi 2003). More frequently, elderly patients with GERD report symptoms such as dysphagia, vomiting and respiratory difficulties, anorexia, weight loss, and anemia-melena (Pilotto and Franceschi 2003). Because of this different symptom profile of GERD in the elderly, the disease, particularly in milder form, may remain undiagnosed for a considerable period of time (Maekawa et al 1998) resulting in hospital admittance for more severe disease (Zimmerman et al 1997). 
Elderly patients require endoscopy as the initial diagnostic test for GERD, irrespective of the severity or duration of their symptoms - endoscopy is even indicated in elderly patients without current typical symptoms, but with a past history of GERD (Richter 2000). However, endoscopy can be associated with the risk of complications, particularly in elderly patients with heart or pulmonary disease, and so use of well validated symptom assessment tools may increasingly have a role in the diagnosis and long term management of GERD in elderly patients. Based on their safety profiles and success in the general patient population, PPIs as a class are considered first-line treatment for GERD and erosive esophagitis in the elderly (Bacak et al 2006).

Results of a retrospective analysis, based on combined data from two prospective, double-blind, randomized trials in patients with Hetzel-Dent grade $\geq 2$ erosive esophagitis, show that healing rates with pantoprazole $40 \mathrm{mg}$ are similar in elderly patients and in younger patients. At 8 weeks, healing rates were $86 \%$ in the 44 patients aged $\geq 65$ years and $83 \%$ in the 210 patients aged $<65$ years. Pantoprazole was more effective than a combined placebo/nizatidine treatment group $(\mathrm{p}<0.001)$ (DeVault et al 2003).

Results of a prospective study have confirmed the efficacy of oral pantoprazole in 164 patients aged $\geq 65$ years with Savary-Miller grade I-III GERD. Patients initially received pantoprazole $40 \mathrm{mg}$ daily for 8 weeks and $81 \%$ achieved documented healing of erosive esophagitis. All healed patients subsequently received maintenance therapy with pantoprazole $20 \mathrm{mg}$ daily; $82 \%$ remained in remission at 6 months. Continued therapy with pantoprazole $20 \mathrm{mg}$ daily for a further 6 months maintained a remission rate of $80 \%$ at 1 year, whereas switching to placebo for the last 6 months of the trial resulted in a remission rate of $30 \%$ (Pilotto et al 2003). These results show that pantoprazole is highly effective for healing and reducing the relapse of erosive esophagitis, and that discontinuing active treatment after 6 months is associated with a significant increase in the risk of relapse. In this study, the most commonly reported adverse events were glossitis, headache, and diarrhea. These findings are in agreement with data for nonelderly populations.

When treating elderly patients with GERD, concomitant medications should be considered for two main reasons. Firstly, it is known that a number of medications commonly prescribed for elderly patients may promote gastroesophageal reflux and, secondly, drug interactions may be of particular importance in these patients as they are frequently receiving multiple drug therapies (Pilotto et al 2005; Gorard 2006;
Steinman et al 2006). When considering treatment with PPIs, it is important to note that interactions caused by changes in gastric $\mathrm{pH}$ are a group-specific effect, but each PPI differs in its propensity to interact with other drugs and the extent to which its interaction profile has been defined. The interaction profiles of omeprazole and pantoprazole have been studied most extensively: omeprazole carries a considerable potential for drug interactions, whereas pantoprazole appears to have lower potential for interactions with other medications. The interaction profiles of esomeprazole, lansoprazole, and rabeprazole have been less extensively investigated, but evidence suggests that lansoprazole and rabeprazole have weaker potentials for interactions than omeprazole, and esomeprazole has a propensity for drug interactions similar to that of omeprazole. (Blume et al 2006). This pharmacokinetic profile suggests that pantoprazole is well suited for use in elderly patients who as a group frequently present with comorbidities and receive multiple therapies.

\section{Conclusion}

The optimal treatment of GERD is vital for a number of reasons. GERD is a chronic, relapsing disease that can progress to major complications; affected patients have significantly poorer health-related quality of life than the general population, with impairment being proportional to the frequency and severity of symptoms; and as GERD requires continued therapy to prevent relapse and complications, most patients with erosive esophagitis require long-term acid suppressive treatment. Thus GERD results in a significant cost burden.

The effective treatment of GERD provides symptom resolution and high rates of remission in erosive esophagitis, lowers the incidence of GERD complications, improves health-related quality of life and reduces the cost of this disease. PPIs are accepted as the most effective treatment for GERD and are the mainstay of initial GERD management, providing more rapid symptom control and better healing of erosive esophagitis than $\mathrm{H}_{2}$-receptor antagonists and antacids. PPIs are also the preferred agents for maintenance therapy in patients with healed erosive esophagitis (Lauritsen et al 2003). As few differences in safety or efficacy have been reported between the available PPIs, the decision to select one PPI over another is most likely to be based on the agents' acquisition costs, formulations, Food and Drug Administration-labeled indications, and overall safety profiles (Welage and Berardi 2000).

The data reviewed here show that oral pantoprazole is a safe, well tolerated and effective initial and maintenance 
treatment for patients with nonerosive GERD or erosive esophagitis. Oral pantoprazole has greater efficacy than that of $\mathrm{H}_{2}$-receptor antagonists and generally has similar efficacy to other PPIs for the initial and maintenance treatment of GERD. In addition, oral pantoprazole has been shown to improve the quality of life of patients with GERD and is associated with high levels of patient satisfaction with therapy. GERD appears to be more common and more severe in the elderly. Furthermore, as elderly are taking multiple medications at the same time, or drugs with a narrow therapeutic window, drug interactions may be of particular importance in those patients. Pantoprazole has also shown to be an effective and safe treatment for this at-risk population.

\section{References}

Achim A, Riddermann T, Pfaffenberger B, et al. 2005. Pantoprazole $40 \mathrm{mg}$ is at least comparable to esomeprazole $40 \mathrm{mg}$ in achieving endoscopically confirmed healing and symptom relief of gastroesophageal reflux disease (GERD) after 4, 8 and 12 weeks of treatment. Can J Gastroenterol, 19(Suppl C):DR.0038.

Adamek RJ, Behrendt J, Wenzel C. 2001. Relapse prevention in reflux oesophagitis with regard to Helicobacter pylori status: a doubleblind, randomized, multicentre trial to compare the efficacy of pantoprazole versus ranitidine. Eur J Gastroenterol Hepatol, 13:811-17.

Arango L, Angel A, Molina RI, et al. 2000. Comparison between digestive endoscopy and 24-hour esophageal $\mathrm{pH}$ monitoring for the diagnosis of gastroesophageal reflux esophagitis: "presentation of 100 cases." Hepatogastroenterology, 47:174-80.

Arnold R. 1994. Safety of proton pump inhibitors - an overview. Aliment Pharmacol Ther, 8:65-70.

Bacak BS, Patel M, Tweed E, et al. 2006. What is the best way to manage GERD symptoms in the elderly? J Fam Pract, 55:251-4,8.

Bardhan KD. 2003. Intermittent and on-demand use of proton pump inhibitors in the management of symptomatic gastroesophageal reflux disease. Am J Gastroenterol, 98:S40-8.

Bardhan KD, Cherian P, Bishop AE, et al. 2001. Pantoprazole therapy in the long-term management of severe acid peptic disease: clinical efficacy, safety, serum gastrin, gastric histology, and endocrine cell studies. $\mathrm{Am}$ J Gastroenterol, 96:1767-76.

Bell NJ, Hunt RH. 1992. Progress with proton pump inhibition. Yale J Biol Med, 65:649-57; discussion 89-92.

Bloom BS, Jayadevappa R, Wahl P, et al. 2001. Time trends in cost of caring for people with gastroesophageal reflux disease. Am J Gastroenterol, 96:S64-9.

Blume H, Donath F, Warnke A, et al. 2006. Pharmacokinetic drug interaction profiles of proton pump inhibitors Drug Safety, 29:769-84.

Bochenek WJ, Mack ME, Fraga PD, et al. 2004. Pantoprazole provides rapid and sustained symptomatic relief in patients treated for erosive oesophagitis. Aliment Pharmacol Ther, 20:1105-14.

Bollschweiler E, Wolfgarten E, Gutschow C, et al. 2001. Demographic variations in the rising incidence of esophageal adenocarcinoma in white males. Cancer, 92:549-55.

Carlsson R, Dent J, Watts R, et al. 1998. Gastro-oesophageal reflux disease in primary care: an international study of different treatment strategies with omeprazole. International GORD Study Group. Eur J Gastroenterol Hepatol, 10:119-24.
Caro JJ, Salas M, Ward A. 2001. Healing and relapse rates in gastroesophageal reflux disease treated with the newer proton-pump inhibitors lansoprazole, rabeprazole, and pantoprazole compared with omeprazole, ranitidine, and placebo: evidence from randomized clinical trials. Clin Ther, 23:998-1017.

Cheer SM, Prakash A, Faulds D, et al. 2003. Pantoprazole: an update of its pharmacological properties and therapeutic use in the management of acid-related disorders. Drugs, 63:101-33.

Chiba N. 1997. Proton pump inhibitors in acute healing and maintenance of erosive or worse esophagitis: a systematic overview. Can $J$ Gastroenterol, 11(Suppl B):66B-73B.

Chiba N, De Gara CJ, Wilkinson JM, et al. 1997. Speed of healing and symptom relief in grade II to IV gastroesophageal reflux disease: a meta-analysis. Gastroenterology, 112:1798-810.

Crawley JA, Maclin Schmitt C. 2000. How satisfied are chronic heartburn sufferers with their prescription medications? Results of the patient unmet needs survey. J Clin Outcomes Manag, 7:29-34.

Csendes A, Smok G, Cerda G, et al. 1997. Prevalence of Helicobacter pylori infection in 190 control subjects and in 236 patients with gastroesophageal reflux, erosive esophagitis or Barrett's esophagus. Dis Esophagus, 10:38-42.

Dajani EZ. 2000. Gastroesophageal reflux disease: pathophysiology and pharmacology overview. J Assoc Acad Minor Phys, 11:7-11.

Dent J, Brun J, Fendrick A, et al. 1999. An evidence-based appraisal of reflux disease management - the Genval Workshop report. Gut, 44:S1-S16.

de-Souza-Cury M, Ferrari AP, Ciconelli R, et al. 2006. Evaluation of health-related quality of life in gastroesophageal reflux disease patients before and after treatment with pantoprazole. Diseases of the Esophagus, 19:289-93.

DeVault K, Lynn R, Bochenek W, et al. 2003. Successful treatment of elderly patients with erosive esophagitis (EE) using pantoprazole $40 \mathrm{mg} . A m J$ Gastroenterol, Sep(Suppl.):S3.

DeVault KR, Castell DO. 1999. Updated guidelines for the diagnosis and treatment of gastroesophageal reflux disease. The Practice Parameters Committee of the American College of Gastroenterology. Am J Gastroenterol, 94:1434-42.

DeVault K, Malagelada J, Holtmann G, et al. 2006. GERDyzer ${ }^{\mathrm{rM}}$ treatment satisfaction module: correlation with symptom assessment by ReQuest $^{\mathrm{TM}}$ - GI (abstract). Am J Gastroenterol, 101(Suppl. 2):S-400.

Dimenas E, Carlsson G, Glise H, et al. 1996. Relevance of norm values as part of the documentation of quality of life instruments for use in upper gastrointestinal disease. Scand J Gastroenterol Suppl, 221:8-13.

Dimenas E, Glise H, Hallerback B, et al. 1993. Quality of life in patients with upper gastrointestinal symptoms. An improved evaluation of treatment regimens? Scand J Gastroenterol, 28:681-7.

Donnellan C, Sharma N, Preston C, et al. 2004. Medical treatments for the maintenance therapy of reflux oesophagitis and endoscopic negative reflux disease. Cochrane Database Syst Rev, 4:CD003245.

El-Serag HB, Sonnenberg A. 1997. Associations between different forms of gastro-oesophageal reflux disease. Gut, 41:594-9.

Enck P, Dubois D, Marquis P. 1999. Quality of life in patients with upper gastrointestinal symptoms: results from the Domestic/International Gastroenterology Surveillance Study (DIGEST). Scand J Gastroenterol Suppl, 231:48-54.

Escourrou J, Deprez P, Saggioro A, et al. 1999. Maintenance therapy with pantoprazole $20 \mathrm{mg}$ prevents relapse of reflux oesophagitis. Aliment Pharmacol Ther, 13:1481-91.

Farup C, Kleinman L, Sloan S, et al. 2001a. The impact of nocturnal symptoms associated with gastroesophageal reflux disease on healthrelated quality of life. Arch Intern Med, 161:45-52.

Farup C, Kleinman L, Sloan S, et al. 2001b. The impact of nocturnal symptoms associated with gastroesophageal reflux disease on healthrelated quality of life. Arch Intern Med, 161:45-52.

Fass R, Ofman JJ, Gralnek IM, et al. 1999. Clinical and economic assessment of the omeprazole test in patients with symptoms suggestive of gastroesophageal reflux disease. Arch Intern Med, 159:2161-8. 
Fass R, Ofman JJ, Sampliner RE, et al. 2000. The omeprazole test is as sensitive as $24-\mathrm{h}$ oesophageal $\mathrm{pH}$ monitoring in diagnosing gastrooesophageal reflux disease in symptomatic patients with erosive oesophagitis. Aliment Pharmacol Ther, 14:389-96.

Fendrick AM. 2001. Management of patients with symptomatic gastroesophageal reflux disease: a primary care perspective. $\mathrm{Am} J$ Gastroenterol, 96:S29-33.

Fennerty MB, Zuckerman S, Spreen KA. 2002. Heartburn severity does not predict disease severity in gastroesophageal reflux patients with erosive esophagitis. Las Vegas, NV: American Osteopathic Association.

Freston JW. 1997. Long-term acid control and proton pump inhibitors: interactions and safety issues in perspective. Am J Gastroenterol, 92:51S-5S; discussion 5S-7S.

Gillessen A, Beil W, Modlin IM, et al. 2004. 40 mg pantoprazole and $40 \mathrm{mg}$ esomeprazole are equivalent in the healing of esophageal lesions and relief from gastroesophageal reflux disease-related symptoms. $J$ Clin Gastroenterol, 38:332-40.

Glatzel D, Abdel-Qader M, Gatz G, et al. 2006. Pantoprazole $40 \mathrm{mg}$ is as effective as esomeprazole $40 \mathrm{mg}$ to relieve symptoms of gastroesophageal reflux disease (GERD) after 4 weeks of treatment and superior regarding prevention of symptomatic relapse. Digestion, 74:145-54.

Goh K, Wu C, Benamouzig R, Sander P, et al. 2007. Efficacy of Pantoprazole $20 \mathrm{mg}$ daily compared to Esomeprazole $20 \mathrm{mg}$ daily in the maintenance of gastroesophageal reflux disease: a randomized, double-blind comparative trial: the EMANCIPATE study. Euro J Gastro Hepatol, 19:205-11.

Gorard DA. 2006. Escalating polypharmacy. QJM, 99:797-800

Green J. 1993. Is there such an entity as mild oesophagitis? Eur J Clin Res, 4:29-34.

Haag S, Holtmann G. 2003. Reflux disease and Barrett's esophagus. Endoscopy, 35:112-17.

Habermann W, Kiesler K, Eherer A, et al. 2002. Short-term therapeutic trial of proton pump inhibitors in suspected extraesophageal reflux. $J$ Voice, 16:425-32.

Halstead LA. 2005. Extraesophageal manifestations of GERD: diagnosis and therapy. Drugs Today (Barc), 41(Suppl B):19-26.

Heinze H, Preinfalk J, Athmann C, et al. 2003. Clinical efficacy and safety of pantoprazole in severe acid-peptic disease during up to 10 years maintenance treatment. Gut, 52(Suppl. VI):A63.

Henke CJ, Levin TR, Henning JM, et al. 2000. Work loss costs due to peptic ulcer disease and gastroesophageal reflux disease in a health maintenance organization. Am J Gastroenterol, 95:788-92.

Hetzel DJ, Dent J, Reed WD, et al. 1988. Healing and relapse of severe peptic esophagitis after treatment with omeprazole. Gastroenterology, 95:903-12.

Hollenz M, Stolte M, Labenz J. 2002. Prevalence of gastro-oesophageal reflux disease in general practice. Deutsche Medizinische Wochenschrift, 127:1007-12.

Holtmann G, Chassany O, DeVault K, et al. 2005. GERDyzer ${ }^{\mathrm{TM}}$ : validation of a new scale for the assessment of health related quality of life in gastroesophageal reflux disease (GERD) [abstract]. Gut, 54 (Suppl. VII): A-52

Holtmann G, DeVault K, Chassany O, et al. 2006a. Fast onset of action the initial dose of pantoprazole is superior to esomeprazole in reducing the frequence and intensity of acid episodes determined by ReQuest ${ }^{\mathrm{TM}}$ [abstract]. Gut, 55(Suppl. V):A271.

Holtmann G, Malagelada J, Chassany O, et al. 2006b. Gender and age influence health-related quality of life (HRQoL) in GERD: patients assessed by GERDyzerTM [abstract]. Gut, 55(Suppl V):A269.

Holzer SS, Juday TR, Joelsson B, et al. 1998. Determining the cost of gastroesophageal reflux disease: a decision analytic model. Am J Manag Care, 4:1450-60.

Johansson KE, Ask P, Boeryd B, et al. 1986. Oesophagitis, signs of reflux, and gastric acid secretion in patients with symptoms of gastrooesophageal reflux disease. Scand J Gastroenterol, 21:837-47.
Johnson DA. 2003. Endoscopic therapy for GERD — baking, sewing, or stuffing: an evidence-based perspective. Rev Gastroenterol Disord, 3:142-9.

Johnson DA, Fennerty MB. 2004. Heartburn severity underestimates erosive esophagitis severity in elderly patients with gastroesophageal reflux disease. Gastroenterology, 126:660-4.

Kahrilas PJ, Fennerty MB, Joelsson B. 1999. High- versus standard-dose ranitidine for control of heartburn in poorly responsive acid reflux disease: a prospective, controlled trial. Am J Gastroenterol, 94:92-7.

Kaplan-Machlis B, Spiegler GE, Revicki DA. 1999. Health-related quality of life in primary care patients with gastroesophageal reflux disease. Ann Pharmacother, 33:1032-6.

Kaspari S, Biedermann A, Mey J. 2001. Comparison of pantoprazole 20 $\mathrm{mg}$ to ranitidine $150 \mathrm{mg}$ bid in the treatment of mild gastroesophageal reflux disease. Digestion, 63:163-70.

Kaspari S, Kupcinskas L, Heinze H, et al. 2005. Pantoprazole $20 \mathrm{mg}$ on demand is effective in the long-term management of patients with mild gastro-oesophageal reflux disease. Eur J Gastroenterol Hepatol, 17:935-41.

Kulig M, Leodolter A, Vieth M, et al. 2003. Quality of life in relation to symptoms in patients with gastro-oesophageal reflux disease - an analysis based on the ProGERD initiative. Aliment Pharmacol Ther, 18:767-76.

Labenz J, Armstrong D, Lauritsen K, et al. 2005. Esomeprazole 20 mg vs. pantoprazole $20 \mathrm{mg}$ for maintenance therapy of healed erosive oesophagitis: results from the EXPO study. Aliment Pharmacol Ther, 22:803-11.

Labenz J, Malfertheiner P. 1997. Helicobacter pylori in gastro-oesophageal reflux disease: causal agent, independent or protective factor? Gut, 41:277-80.

Labenz J, Petersen KU, Rosch W, et al. 2003. A summary of Food and Drug Administration-reported adverse events and drug interactions occurring during therapy with omeprazole, lansoprazole and pantoprazole. Aliment Pharmacol Ther, 17:1015-19.

Lagergren J, Bergström R, Lindgren A, et al. 1999. Symptomatic gastroesophageal reflux as a risk factor for esophageal adenocarcinoma. N Engl J Med, 340:825-31.

Lassen A, Hallas J, de Muckadell OB. 2006. Esophagitis: incidence and risk of esophageal adenocarcinoma - a population-based cohort study. Am J Gastroenterol, 101:1193-9.

Lauritsen K, Devière J, Bigard MA, et al. 2003. Esomeprazole $20 \mathrm{mg}$ and lansoprazole $15 \mathrm{mg}$ in maintaining healed reflux oesophagitis: Metropole study results. Am J Gastroenterol, 17:1-9.

Lauritsen K, Jaup B, Carling L, et al. 2000. Comparable efficacy of pantoprazole and omeprazole to prevent relapse in patients with GERD [abstract]. Gut, 47(Suppl. III):A60.

Lundell L, Miettinen P, Myrvold HE, et al. 2000. Long-term management of gastro-oesophageal reflux disease with omeprazole or open antireflux surgery: results of a prospective, randomized clinical trial. The Nordic GORD Study Group. Eur J Gastroenterol Hepatol, 12:879-87.

Madrazo-de la Garza A, Dibildox M, Vargas A, et al. 2003. Efficacy and safety of oral pantoprazole $20 \mathrm{mg}$ given once daily for reflux esophagitis in children. J Pediatr Gastroenterol Nutr, 36:261-5.

Maekawa T, Kinoshita Y, Okada A, et al. 1998. Relationship between severity and symptoms of reflux oesophagitis in elderly patients in Japan. J Gastroenterol Hepatol, 13:927-30.

Malagelada J, Chassany O, DeVault K, et al. 2006. Health-related quality of life (HRQoL) in GERD patients is significantly influenced by gastrointestinal symptoms [abstract]. Gut, 55(Suppl. V):A253.

McDougall NI, Johnston BT, Kee F, et al. 1996. Natural history of reflux oesophagitis: a 10 year follow up of its effect on patient symptomatology and quality of life. Gut, 38:481-6.

Metz DC, Bochenek WJ. 2003. Pantoprazole maintenance therapy prevents relapse of erosive oesophagitis. Aliment Pharmacol Ther, 17:155-64.

Mold JW, Reed LE, Davis AB, et al. 1991. Prevalence of gastroesophageal reflux in elderly patients in a primary care setting. Am J Gastroenterol, 86:965-70. 
Mossner J, Koop H, Porst H, et al. 1997. One-year prophylactic efficacy and safety of pantoprazole in controlling gastro-oesophageal reflux symptoms in patients with healed reflux oesophagitis. Aliment Pharmacol Ther, 11:1087-92.

Mulder CJ, Westerveld BD, Smit JM, et al. 2002. A double-blind, randomized comparison of omeprazole Multiple Unit Pellet System (MUPS) $20 \mathrm{mg}$, lansoprazole $30 \mathrm{mg}$ and pantoprazole $40 \mathrm{mg}$ in symptomatic reflux oesophagitis followed by 3 months of omeprazole MUPS maintenance treatment: a Dutch multicentre trial. Eur $J$ Gastroenterol Hepatol, 14:649-56.

Myrvold HE, Lundell L, Miettinen P, et al. 2001. The cost of long term therapy for gastro-oesophageal reflux disease: a randomised trial comparing omeprazole and open antireflux surgery. Gut, 49:488-94.

Netzer P, Brabetz-Hofliger A, Brundler R, et al. 1998. Comparison of the effect of the antacid Rennie versus low-dose $\mathrm{H}_{2}$-receptor antagonists (ranitidine, famotidine) on intragastric acidity. Aliment Pharmacol Ther, 12:337-42.

Numans ME, Lau J, de Wit NJ, et al. 2004. Short-term treatment with proton-pump inhibitors as a test for gastroesophageal reflux disease: a meta-analysis of diagnostic test characteristics. Ann Intern Med, 140:518-27.

Nwokolo CU, Smith JT, Gavey C, et al. 1990. Tolerance during 29 days of conventional dosing with cimetidine, nizatidine, famotidine or ranitidine. Aliment Pharmacol Ther, 4(Suppl 1):29-45.

Orlando R. 1999. Reflux esophagitis. In: Yamada T, Alpers D, et al (ed). Textbook of gastroenterology. Philadelphia: Lippincott Williams \& Wilkins. pp 1235-63.

Orlando RC. 1997. The pathogenesis of gastroesophageal reflux disease: the relationship between epithelial defense, dysmotility, and acid exposure. Am J Gastroenterol, 92:3S-5S; discussion S-7S.

Orlando RC. 2006. Current understanding of the mechanisms of gastrooesophageal reflux disease. Drugs, 66(Suppl 1):1-5; discussion 29-33.

Pare P, Armstrong D, Pericak D, et al. 2003. Pantoprazole rapidly improves health-related quality of life in patients with heartburn: a prospective, randomized, double blind comparative study with nizatidine. $J$ Clin Gastroenterol, 37:132-8.

Pilotto A, Franceschi M. 2003. Gastro-esophageal reflux disease in the elderly. In: Pilotto A, Malfertheiner P, Holt P (ed). Aging and the gastrointestinal tract. Interdisciplinary topics in gerontology. Basel: Karger Press, pp 100-17.

Pilotto A, Franceschi M, Paris F. 2005. Recent advances in the treatment of GERD in the elderly: focus on proton pump inhibitors. Int $J$ Clin Pract, 59:1204-9.

Pilotto A, Leandro G, Franceschi M. 2003. Short- and long-term therapy for reflux oesophagitis in the elderly: a multi-centre, placebo-controlled study with pantoprazole. Aliment Pharmacol Ther, 17:1399-406.

Plein K, Hotz J, Wurzer H, et al. 2000. Pantoprazole $20 \mathrm{mg}$ is an effective maintenance therapy for patients with gastro-oesophageal reflux disease. Eur J Gastroenterol Hepatol, 12:425-32.

Prasad M, Rentz AM, Revicki DA. 2003. The impact of treatment for gastro-oesophageal reflux disease on health-related quality of life: a literature review. Pharmacoeconomics, 21:769-90.

Raghunath A, Hungin AP, Wooff D, et al. 2003. Prevalence of Helicobacter pylori in patients with gastro-oesophageal reflux disease: systematic review. $B M J, 326: 737$.

Rai A, Orlando R. 1998. Gastroesophageal reflux disease. Cur Opin Gastroenterol, 14:326-33.

Räihä I, Hietanen E, Sourander L. 1991. Symptoms of gastro-oesophageal reflux disease in elderly people. Age Ageing, 20:365-70.

Revicki DA, Crawley JA, Zodet MW, et al. 1999. Complete resolution of heartburn symptoms and health-related quality of life in patients with gastrooesophageal reflux disease. Aliment Pharmacol Ther, 13:1621-30.

Revicki DA, Wood M, Maton PN, et al. 1998. The impact of gastroesophageal reflux disease on health-related quality of life. Am J Med, 104:252-8.
Richter JE. 2000. Gastroesophageal reflux disease in the older patient: presentation, treatment, and complications. Am J Gastroenterol, 95:368-73.

Richter JE, Bochenek W. 2000. Oral pantoprazole for erosive esophagitis: a placebo-controlled, randomized clinical trial. Pantoprazole US GERD Study Group. Am J Gastroenterol, 95:3071-80.

Richter JE, Fraga P, Mack M, et al. 2004. Prevention of erosive oesophagitis relapse with pantoprazole. Aliment Pharmacol Ther, 20:567-75.

Robinson M, Horn J. 2003. Clinical pharmacology of proton pump inhibitors: what the practising physician needs to know. Drugs, 63:2739-54.

Ruigomez A, Garcia Rodriguez LA, Wallander MA, et al. 2004. Natural history of gastro-oesophageal reflux disease diagnosed in general practice. Aliment Pharmacol Ther, 20:751-60.

Sachs G. 1997. Proton pump inhibitors and acid-related diseases. Pharmacotherapy, 17:22-37.

Sandler RS, Everhart JE, Donowitz M, et al. 2002. The burden of selected digestive diseases in the United States. Gastroenterology, 122:1500-11.

Scholten T, Bohuschke M, Gatz G. 2005. On-demand therapy with pantoprazole $20 \mathrm{mg}$ leads to lower heartburn intensity than with esomeprazole $20 \mathrm{mg}$ in patients with mild GERD. Gut, 54(Suppl. VII):A-109.

Scholten T, Dekkers CP, Schutze K, et al. 2005. On-demand therapy with pantoprazole $20 \mathrm{mg}$ as effective long-term management of reflux disease in patients with mild GERD: the ORION trial. Digestion, $72: 76-85$.

Scholten T, Gatz G, Hole U. 2003. Once-daily pantoprazole $40 \mathrm{mg}$ and esomeprazole $40 \mathrm{mg}$ have equivalent overall efficacy in relieving GERD-related symptoms. Aliment Pharmacol Ther, 18:587-94.

Shaker R, Castell DO, Schoenfeld PS, et al. 2003. Nighttime heartburn is an under-appreciated clinical problem that impacts sleep and daytime function: the results of a Gallup survey conducted on behalf of the American Gastroenterological Association. Am J Gastroenterol, 98:1487-93.

Sharma P, Vakil N. 2003. Review article: Helicobacter pylori and reflux disease. Aliment Pharmacol Ther, 17:297-305.

Shaw MJ, Fendrick AM, Kane RL, et al. 2001. Self-reported effectiveness and physician consultation rate in users of over-the-counter histamine-2 receptor antagonists. Am J Gastroenterol, 96:673-6.

Sontag SJ, Sonnenberg A, Schnell TG, et al. 2006. The long-term natural history of gastroesophageal reflux disease. J Clin Gastroenterol, 40:398-404

Spechler SJ, Goyal RK. 1986. Barrett's esophagus. N Engl J Med, 315:362-71.

Spechler SJ, Lee E, Ahnen D, et al. 2001. Long-term outcome of medical and surgical therapies for gastroesophageal reflux disease: follow-up of a randomized controlled trial. JAMA, 285:2331-8.

Stanghellini V, Armstrong D, Monnikes H, et al. 2005. Determination of ReQuest-based symptom thresholds to define symptom relief in GERD clinical studies. Digestion, 71:145-51.

Steinman MA, Landefeld CS, Rosenthal GE, et al. 2006. Polypharmacy and prescribing quality in older people. J Am Geriatr Soc, 54:1516-23.

Tefera L, Fein M, Ritter MP, et al. 1997. Can the combination of symptoms and endoscopy confirm the presence of gastroesophageal reflux disease? Am Surg, 63:933-6.

Tolia V, Bishop P, Tsou V, et al. 2006. Multicenter, randomized, doubleblind study comparing 10,20 and $40 \mathrm{mg}$ pantoprazole in children (5-11 years) with symptomatic gastroesophageal reflux disease. $J$ Pediatr Gastroenterol Nutr, 42:384-91.

Tsou V, Baker R, Book L, et al. 2006. Multicenter, randomized, double-blind study comparing 20 and $40 \mathrm{mg}$ of pantoprazole for symptom relief in adolescents (12 to 16 years of age) with gastroesophageal reflux disease (GERD). Clin Pediatr, 45:741-9.

Vakil N, Shaw M, Kirby R. 2003. Clinical effectiveness of laparoscopic fundoplication in a U.S. community. Am J Med, 114:1-5. 
Vakil N, van Zanten SV, Kahrilas P, et al. 2006. The Montreal definition and classification of gastroesophageal reflux disease: a global evidencebased consensus. Am J Gastroenterol, 101:1900-20.

Van Herwaarden MA, Samsom M, Smout AJ. 2000. Excess gastroesophageal reflux in patients with hiatus hernia is caused by mechanisms other than transient LES relaxations. Gastroenterology, 119:1439-46.

van Hout BA, Klok RM, Brouwers JR, et al. 2003. A pharmacoeconomic comparison of the efficacy and costs of pantoprazole and omeprazole for the treatment of peptic ulcer or gastroesophageal reflux disease in The Netherlands. Clin Ther, 25:635-46.

van Rensburg CJ, Honiball PJ, Grundling HD, et al. 1996. Efficacy and tolerability of pantoprazole $40 \mathrm{mg}$ versus $80 \mathrm{mg}$ in patients with reflux oesophagitis. Aliment Pharmacol Ther, 10:397-401.

Van Rensburg CJ, Honiball PJ, Van Zyl JH, et al. 1999. Safety and efficacy of pantoprazole $40 \mathrm{mg}$ daily as relapse prophylaxis in patients with healed reflux oesophagitis-a 2-year follow-up. Aliment Pharmacol Ther, 13:1023-8.
Watson DI, Jamieson GG, Baigrie RJ, et al. 1996. Laparoscopic surgery for gastro-oesophageal reflux: beyond the learning curve. Br J Surg, $83: 1284-7$.

Welage LS, Berardi RR. 2000. Evaluation of omeprazole, lansoprazole, pantoprazole, and rabeprazole in the treatment of acid-related diseases. J Am Pharm Assoc (Wash), 40:52-62; quiz 121-3.

Wiklund I, Bardhan KD, Muller-Lissner S, et al. 1998. Quality of life during acute and intermittent treatment of gastro-oesophageal reflux disease with omeprazole compared with ranitidine. Results from a multicentre clinical trial. The European Study Group. Ital J Gastroenterol Hepatol, 30:19-27.

Wyeth JW, Pounder RE, Sercombe JC, et al. 1998. The effects of low doses of ranitidine on intragastric acidity in healthy men. Aliment Pharmacol Ther, 12:255-61.

Zimmerman J, Shohat V, Tsvang E, et al. 1997. Esophagitis is a major cause of upper gastrointestinal hemorrhage in the elderly. Scand $J$ Gastroenterol, 32:906-9. 
